\title{
DESIGN OF SHAKE TABLE TESTS OF MULTI-LEAF MASONRY WALLS BEFORE AND AFTER RETROFITTING
}

\section{STEFANO DE SANTIS ${ }^{1, *}$, OMAR ALSHAWA ${ }^{2}$, GERARDO DE CANIO ${ }^{3}$, SARA FORLITI $^{3}$, DOMENICO LIBERATORE ${ }^{2}$, PIETRO MERIGGI ${ }^{1}$, IVAN ROSELLI ${ }^{3}$, LUIGI SORRENTINO ${ }^{2}$, AND GIANMARCO DE FELICE ${ }^{1}$}

\author{
${ }^{1}$ Department of Engineering, Roma Tre University \\ Via Vito Volterra 62, 00146 Rome, Italy \\ Email: \{ stefano.desantis, pietro.meriggi, gianmarco.defelice\}@uniroma3.it \\ Web page: www.romatrestrutture.eu (*corresponding author) \\ ${ }^{2}$ Department of Structural and Geotechnical Engineering, Sapienza University of Rome \\ Via Antonio Gramsci 53, 00197 Rome, Italy \\ e-mail: \{omar.alshawa, domenico.liberatore, luigi.sorrentino\}@uniroma1.it \\ Web page: www.disg.uniroma1.it \\ ${ }^{3}$ Laboratorio Tecnologie per la Dinamica delle Strutture e la Prevenzione del rischio sismico e \\ idrogeologico, ENEA Centro Ricerche Casaccia \\ Via Anguillarese 301, 00123 Santa Maria di Galeria (Rome), Italy \\ Email: \{gerardo.decanio, sara.forliti, ivan.roselli\} @enea.it - Web page: www.enea.it
}

Keywords: 2016-2017 Central Italy Earthquake, 3DVision, Composite materials, Natural accelerogram, Seismic retrofitting.

\begin{abstract}
A significant proportion of the built heritage in historic centres is constituted by rubble stone masonry structures. Collapses by leaf separation and disaggregation observed after earthquakes highlight their dramatic vulnerability, especially under out-of-plane loads. Nevertheless, their dynamic response still needs to be fully investigated and their capacity may be overestimated by assessment approaches based on rigid-body mechanics. Effective retrofitting solutions are also needed to protect human lives and safeguard the built heritage, while ensuring the conservation of its architectural value. This paper describes the design of a shake table investigation on stone masonry walls, whose materials and arrangement reproduce those surveyed in the villages of central Italy struck by the 2016-2017 earthquake sequence. The test setup was conceived to induce out-of-plane vertical bending under earthquake base motion and investigate the dynamic response of multi-leaf rubble stone masonry and the gain in seismic capacity that can be achieved with mortar-based composite reinforcements, designed to prevent the leaf separation and disaggregation of the wall without compromising its fair face.
\end{abstract}

\section{INTRODUCTION}

A seismic sequence activated in central Italy in Summer 2016 and struck a number of historic centres located in four regions (Lazio, Marche, Umbria and Abruzzo). The first event occurred 
on August 24th 2016, had a magnitude of $\mathrm{M}_{\mathrm{W}} 6.0$ and its epicentre was in Accumoli (RI, Lazio). Other events followed, the strongest ones being on October 26th 2016 ( $\mathrm{M}_{\mathrm{W}}$ 5.9, Castelsantangelo sul Nera, MC, Marche), October 30th 2016 (Mw 6.5, Norcia, PG, Umbria) and January 18th 2017 (Mw 5.5, Capitignano, AQ, Abruzzo) ${ }^{[1]}$. In addition to the 299 fatalities and almost one thousand people injured, several collapses occurred (the centres of Amatrice, Accumoli and Arquata del Tronto were almost destroyed) and severe damages were surveyed ${ }^{[2]}$. Such scenario is associated with the building stock of the areas struck by the earthquake, mainly constituted by old structures in rubble stone masonry (Figure 1) and ordinary reinforced concrete buildings, including churches and palaces of architectural value ${ }^{[3]}$.

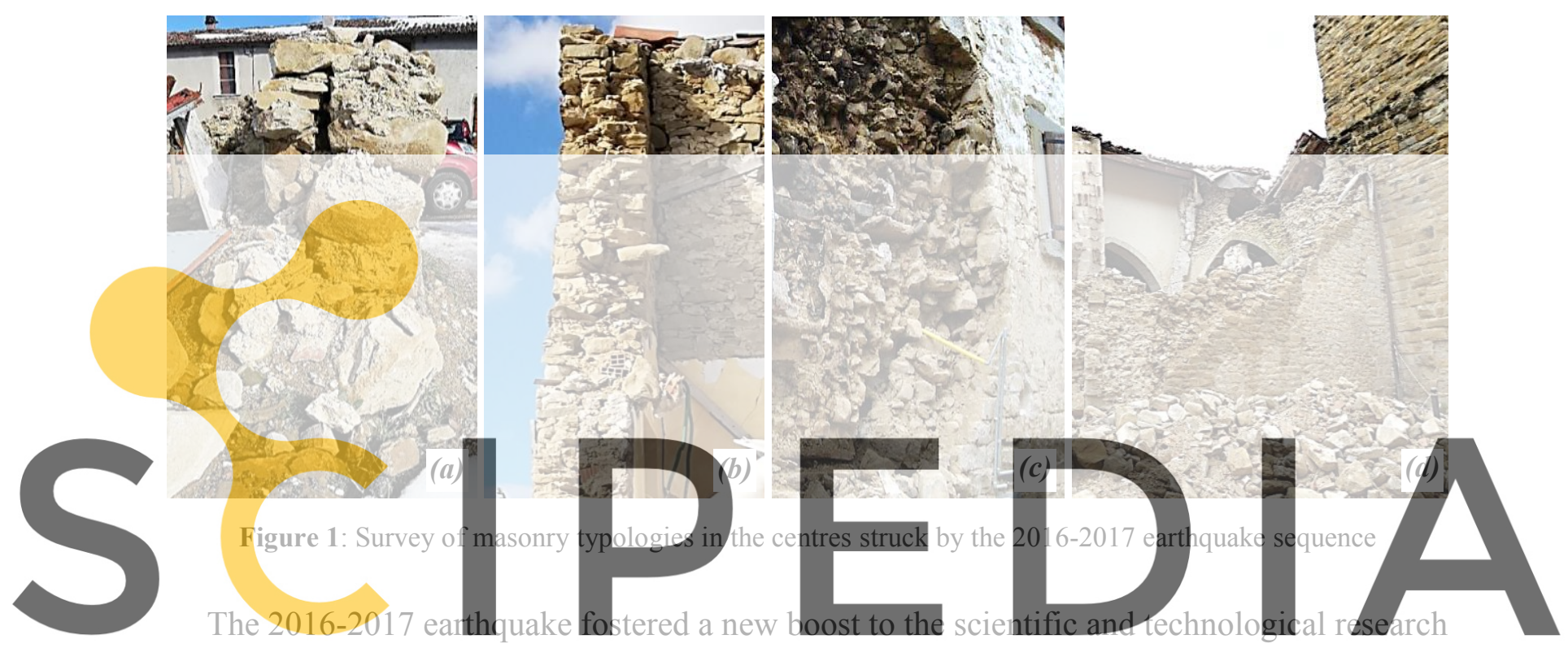

devoted to the seismic assessment and protection of the building stock in earthquake prone

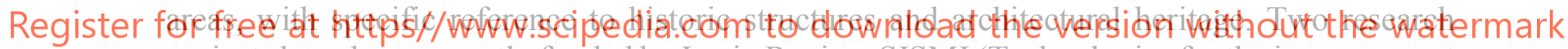
projects have been recently funded by Lazio Region. SISMI (Technologies for the improvement of the seismic safety and the restoration of historical centres) gathers the main research institutions in the Region in a wide range of activities, including architectural survey of the built heritage of the earthquake prone areas of the Region, seismological characterization of the territory, structural assessment tools, smart materials for retrofitting, full-scale tests, and monitoring. SICURA (Sustainable technologies for the seismic protection of the cultural heritage) is coordinated by Roma Tre University and involves suppliers of reinforcement systems, software houses, design companies and contractors. The project aims at developing an advanced knowledge on the seismic retrofitting of architectural heritage with mortar-based composites and includes experiments on small-scale specimens and on full-scale retrofitted structures, and the development of advanced software tools and expeditious analytical methods for the reinforcement design and the assessment of retrofitted structures. Both the projects include shake table tests on full-scale structural members for investigating the seismic response of historic masonry, validating numerical models and demonstrating the effectiveness of strengthening technologies. This paper presents the design of this table test, starting from the identification of the problems under study and including the collection of the materials, the design of the setup, the selection of the inputs, and the development of retrofitting solutions. 


\section{PROBLEM STATEMENT AND GOALS OF THE STUDY}

Rubble stone masonry structures proved extremely vulnerable against seismic actions. Due to their the irregular arrangement (Figure 1a,b), poor quality of the mortars, and weak connection with orthogonal walls and horizontal structures (floor, roof), the perimeter walls tend to separate from the rest of the construction and collapse out of their plane ${ }^{[4]}$. Not only this, but also such type masonry generally fails by leaf separation (Figure 1c) and disaggregation (Figure 1d), such that, on the one hand, tie-bars and crowning beams (possibly installed after past earthquakes) do not effectively prevent collapse and, on the other hand, their seismic capacity may be overestimated by the assessment approaches based on rigid-body mechanics ${ }^{[5]}$. The surveys carried out after the events of the 2016-2017 earthquakes confirmed such feature, highlighting the dramatic fragility of the territories struck by the seismic sequence. Nonetheless, the dynamic response of this type of masonry still needs to be deeply investigated to develop adequate assessment tools and effective retrofitting solutions. With these purposes, a shake table test investigation was designed on four full-scale wall specimens, built with the stones collected in a small village struck by the earthquake and a mortar developed on the basis of the samples taken in the field. The programme includes a first test on one unreinforced wall, followed by the tests on three walls retrofitted with different strengthening solutions. Each specimen will be subjected to a sequence of seismic inputs at the base, along the horizontal direction (out of the plane of the wall) and along the vertical direction, which will be progressively scaled up to collapse. This allows following the development of damage,

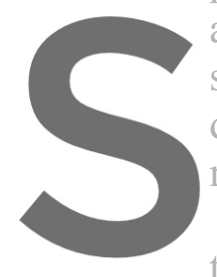
although the test sequence is expected to affect the results an
single input signal that corresponds to the whole sequence.
designed to constrain the top horizontal displacement and le
rotation free, to induce vertical bending under earthquake base
This experimental study requires important efforts for the cons the setup, the implementation in the laborc reinforcements, and the acquisition, analysis and interpretation of test data. On the other hand,

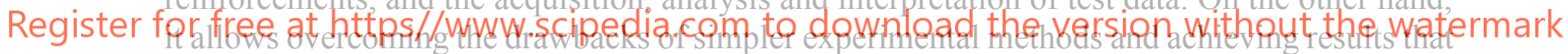

would be unavailable otherwise. First, the investigation of full-scale specimens makes it possible to build the walls and apply the seismic inputs without scale effects. The use of original materials makes it possible to represent the masonry types surveyed in the field, which is essential to investigate their behaviour, replicate their failure modes and assess the effectiveness of retrofitting strategies ${ }^{[6]}$. Placing full-scale walls in vertical (with the addition of masses on top) makes it possible to apply a vertical compression in addition to the out-of-plane loads, thus replicating the stress state experienced by masonry walls in the field, which is unfeasible when medium-scale wall panels are tested with a three/four point bending test configuration ${ }^{[7]}$. Second, the careful design of the constraint that prevents the horizontal displacement of the top of the wall (simulating the effect of a tie-bar or of a crowning beam) while leaving the vertical displacement and the rotation free, aims at reproducing the actual boundary conditions of a façade at the highest storey of a building. Indeed, it has been observed that the dynamic behaviour of a masonry wall under out-of-plane bending is highly affected by the boundary conditions and especially by the restraint imposed to the top vertical displacement ${ }^{[8]}$. Finally, the use of a shake table infrastructure allows the application of acceleration time histories at the base of the specimens, thus reproducing the actual distribution of inertial forces experimented 
by the wall under earthquake base motion, including their dynamic amplification and rapid variation and reversal, which cannot be simulated in quasi-static tests ${ }^{[9]}$. Moreover, the application of the vertical component of the seismic inputs makes it possible to take into account its effects on the dynamic response, which cannot be neglected when unreinforced masonry is under investigation ${ }^{[10]}$.

With these premises, this shake table investigation aims to:

(i) develop a deeper understanding of the seismic behaviour of historic multi-leaf rubble stone masonry walls under out-of-plane loads, with specific reference to boundary conditions that prevent the onset of overturning such that disaggregation, possibly combined with leaf separation, is the expected failure mode;

(ii) contribute to the development of seismic assessment methods that account for the arrangement of masonry and its effect on the dynamic response and failure mode under out-of-plane loads, overcoming the approaches based on rigid-body mechanics recommended by standard codes ${ }^{[5]}$, which may be unconservative if collapse occurs by disaggregation:

(iii) inyestigate the effectiveness of innovative mortar-based composites for the seismic retrofitting of architectural heritage and promote the development and the confident use in rehabilitation practice of strengthening solutions that combine structural effectiveness and fulfilment of conservation principles;

(iv) foster the fruitful cooperation between academia, industrial partners, institutions and
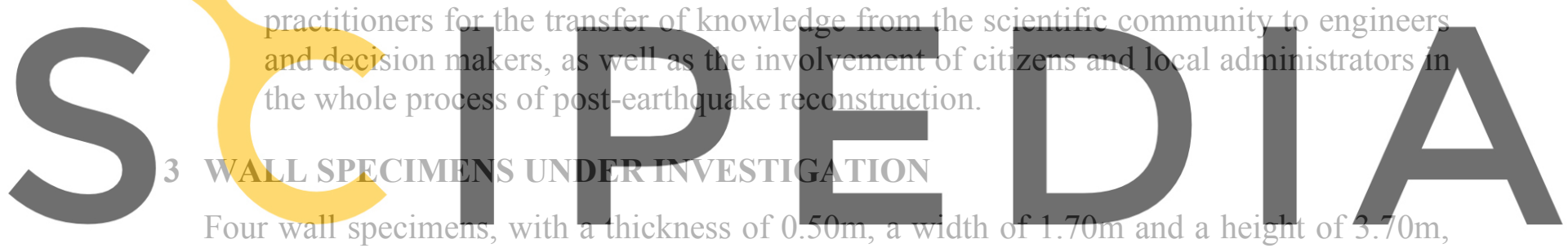

will be tested on the shake table (Figure 2). The walls will be built using rubble limestone units

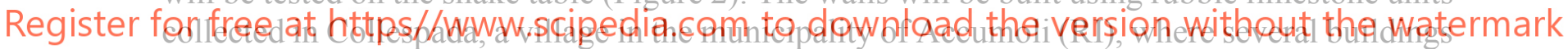

collapsed after the event of October 26th 2016. A mortar with natural aerial lime and siliceous

aggregates will be used, having $1: 9$ binder:aggregate weight ratio and $0 \div 2 \mathrm{~mm}$ grain size range, according to the physical and chemical analyses on mortar samples taken in the field ${ }^{[11]}$. To the purpose of reproducing the arrangement of the masonries surveyed in the historic constructions of central Italy, the walls will have two leaves without transversal connection, small and irregular stones and mortar joints with irregular layout and thickness. Each wall will be built on a reinforced concrete foundation beam, in order to be moved in the laboratory hall and fixed to the shake table (Figure 2a). The first layer of masonry will be partially laid in the foundation to prevent sliding. On top of each wall, a $0.30 \mathrm{~m}$ high top beam will be built in reinforced brickwork. Glass fibre meshes will be placed in the bed joints during construction to provide the top beams with tensile and bending strength. Vertical connectors, inserted in drilled holes injected with a lime-based grout, will ensure the connection with the stone masonry. The top beams will represent a crowning beam built to contribute to their horizontal bending capacity and improve their connection with other orthogonal walls, preventing the onset of out-of-plane overturning mechanisms and providing the structure with a box type behaviour. Finally, a 15 $\mathrm{kN}$ weight will be applied on top to simulate the axial load of a floor or a roof. 


\section{EXPERIMENTAL SETUP AND SEISMIC INPUTS}

\section{Steel frame and setup details}

A steel frame structure will be fixed to the shake table, which is comprised of two braced frames, placed at the two sides of the specimen, and two I-girders, bolted on top of the frames, one on the front side and one on the back side (Figure 2b). Rubber rollers, fixed to the I-girders, will be put in contrast with the top beam in order to constrain its horizontal displacement, while leaving its upward displacement and its rotation free. This setup has already proved effective in a recent experimental investigation ${ }^{[7]}$. The steel structure is designed to minimize the relative displacements between the top beams and the reinforced concrete foundation even if it should be noted that, due to the dynamic amplification of the seismic input over the height of a construction, the dynamic actions at the base and on top are not expected to be identical.

\section{Natural accelerograms selected for the shake table tests}

The acceleration time histories of the main events of the 2016-2017 earthquake sequence will be used in shake table tests. Input signals will be applied along horizontal and vertical directions and progressively scaled up to collapse. The use of different accelerograms will make it possible to investigate the correlation between the response of the wall and several intensity parameters, including peak ground acceleration (PGA), velocity (PGV) and displacement (PGD), Housner intensity, mean incremental velocity (MIV) and spectral acceleration. Data

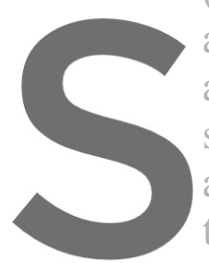
acquisition will be continued for 20 seconds aft
and accelerations under free oscillations and
same reason, tests under white noise will be car
after each sequence of tests with the same scale
the unreinforced specimen will be repeated on
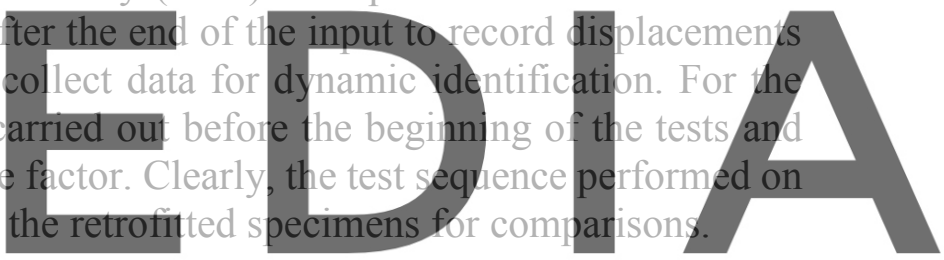

Instrumentation

Register for free at https//www.scipedia.com to download the version without the watermark

The tests will be carried out at ENEA Casaccia Research Centre (Rome) using a $4 \mathrm{~m} \times 4 \mathrm{~m}$

shake table with six degrees of freedom. The accelerations will be recorded by piezoelectric accelerometers placed on the table, on the reinforced concrete foundation, on the wall specimen and on the top beam, in order to detect the actual base input experienced by the walls and their response, including the dynamic amplification throughout the height. A high-resolution optical system named 3DVision will be also used to record the spatial displacements of several measurement points ${ }^{[12]}$. Near infrared digital cameras will be placed around the specimen. LEDs will illuminate wireless retro-reflecting spherical markers and the reflected radiation will be captured by the sensors of the cameras and processed. Displacement data will be filtered to remove noise and analyzed to derive acceleration time histories ${ }^{[13]}$ and calculate fundamental frequencies and modal shapes through Multi-Input/Multi-Output (MIMO) experimental modal analyses ${ }^{[7]}$. Data provided by accelerometers and 3DVision will be compared for mutual validation and for calibrating filter parameters and will integrate each other for a comprehensive detection and representation of test results. 3DVision offers the advantage that the spatial displacement of a large amount of points can be measured during tests, overcoming the limitations of traditional devices associated with encumbrance, range, cables, need of stiff reference structures, and risk of damage to expensive instrumentation. 


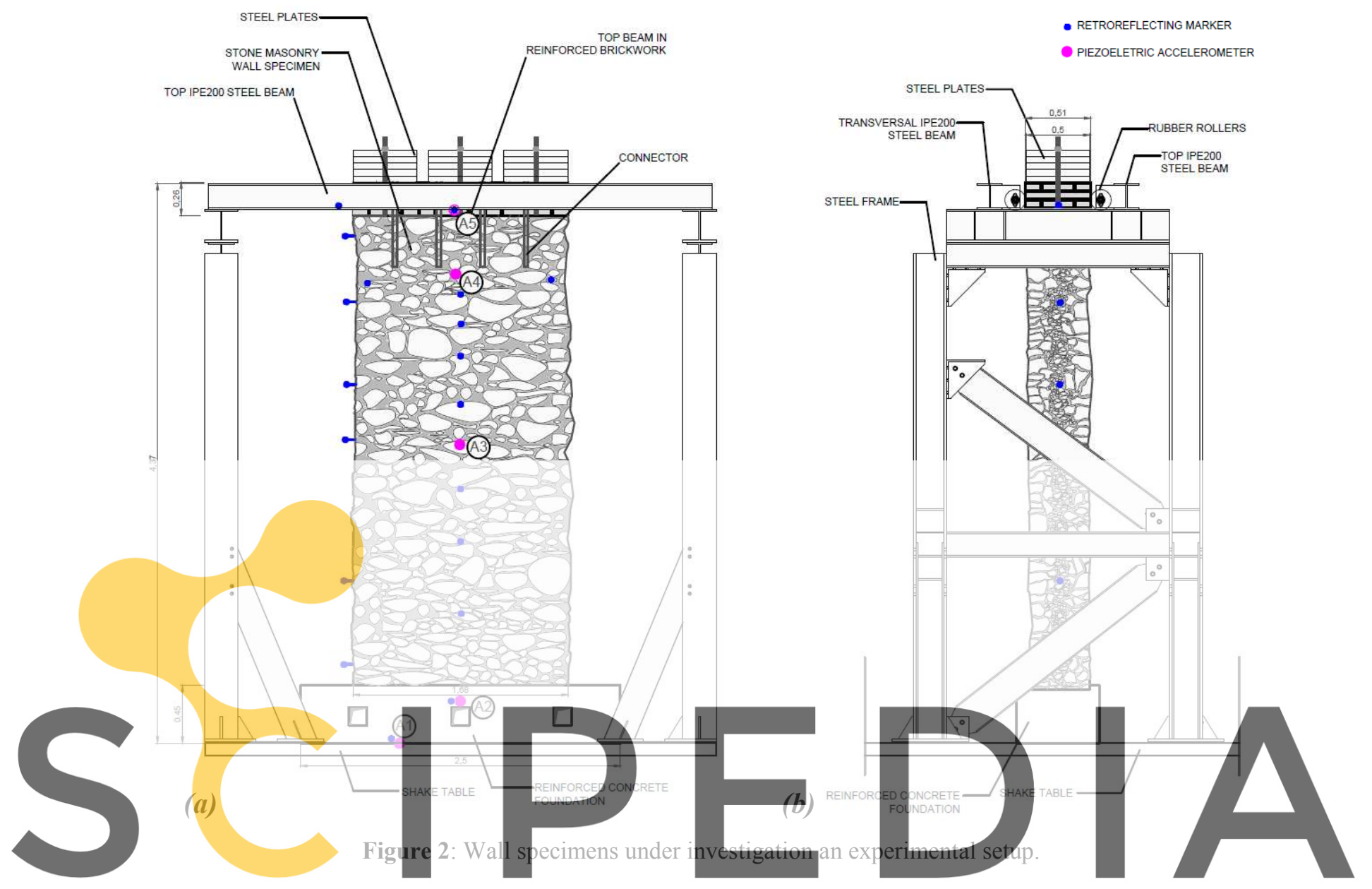

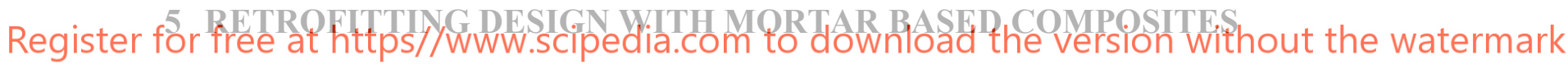 Different retrofitting solutions will be applied to three wall specimens, using mortar-based composites, such as fabric reinforced cementitious matrix (FRCM) ${ }^{[7,14,15]}$ and composite} reinforced mortar (CRM) ${ }^{[16,17]}$. These systems, which have been developed and introduced in the market in the last decade, are comprised of an open mesh applied to the outer surface of the wall with a mortar matrix. They can be seen either as an evolution of ferrocement ${ }^{[18]}$, an overlay of cement plaster applied over one or more layers of a thin steel net, or of Textile Reinforced Concrete (TRC) ${ }^{[19]}$, in which glass or carbon fabrics were used instead of steel nets, to precast thin structural elements. Nevertheless, ferrocement and TRC have been mainly developed for load-bearing new structural members, whereas FRCM and CRM systems are conceived for the external reinforcement of existing structures. They proved effective for enhancing the ultimate capacity of structural members with no increase of mass to the original structure, by the virtue of their high strength-to-weight ratio. The installation is relatively fast and easy, even on uneven or wet substrates, and they can adapt to a broad range of shapes and layouts. When lime-based mortars are used, the retrofitting complies with the principles of conservation as it ensures vapour permeability and physical/chemical compatibility with masonry substrates. In this case, additional challenges are posed by the arrangement of the masonry and its expected failure mode by disaggregation, as well as by the need of preserving its fair face on one side, in order 
to preserve the architectural value of the façade. For these purposes, a hybrid system will be tested, which comprises an FRCM or a CRM overlay installed on one side (the interior one), whereas, on the other side (the façade), mortar joints will be repointed with high strength stainless steel wires ${ }^{[20]}$. On both sides, the retrofitting system will be installed over the whole surface of the wall in order to prevent disaggregation and provide a distributed bending strength. Transversal connectors will be also installed to contrast leaf separation and contribute to the substrate-to-reinforcement load transfer mechanism. The reinforcements are designed in accordance with the guidelines developed by the RILEM Technical Committee 250-CSM jointly with the ACI (American Concrete Institute) 549 Committee ${ }^{[21]}$. The formulation is based on a cross-sectional analysis and assumes ultimate strain values for the materials derived from an acceptance procedure that combines direct tensile and shear bond tests. Tuning coefficients and safety factors are calibrated on experimental databases, as recommended by Eurocodes ${ }^{[22]}$.

\section{FURTHER STEDS AND FYPECTED OUTCOMES}

The outcomes of this investigation will contribute to the development of an improved understanding of the seismic response of historic structures, built in irregular rubble multi-leaf masonry, which, despite their architectural and cultural value, represent a dramatic element of vulnerability in earthquake prone areas. The enhancement of tools for structural assessment as well as of seismic retrofitting technologies will contribute to an improved approach to the seismic protection of the building stock. The transfer of the scientific knowledge developed within this project to angineers, privato and pulpic stakeholder, with the active involvement
general public will foster the implementation of proper structural rehabilitation practices. general public will foster the implementation of proper structural rehabilitation practices.

Acknowledgements. technologies for the Technologies for the imp (2018-2019) funded by Lazio Region. SDS, PM and GdF acknowledge funding from the Italian

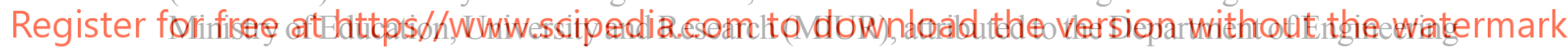
of Roma Tre University, in the frame of the Departments of Excellence Initiative (2018-2022).

\section{REFERENCES}

[1] Mollaioli, F., AlShawa, O., Liberatore, L., Liberatore, D. and Sorrentino, L. Seismic demand of the 2016-2017 Central Italy earthquakes. Bull. Earthq. Eng. (2019) 17(10):5399-5427.

[2] Sorrentino, L., Cattari, S. Da Porto, F., Magenes, G. and Penna, A. Seismic behaviour of ordinary masonry buildings during the 2016 central Italy earthquakes. Bull. Earthq. Eng. (2018) 17(10):5583-5607.

[3] AlShawa, O., De Canio, G., de Felice, G., De Santis, S., Forliti, S., Liberatore, D., Mirabile Gattia, D., Perobelli, S., Persia, F. and Sorrentino, L. Investigation of rubble-masonry wall construction practice in Latium, Central Italy. In: Proceedings of SAHC 2020 Conference.

[4] Lourenço, P.B., Mendes, N., Ramos, L.F. and Oliveira, D.V. Analysis of masonry structures without box behaviour. Int. J. Archit. Herit. (2011) 5(4-5):369-382.

[5] Sorrentino, L., D’Ayala, D., de Felice, G., Griffith, M., Lagomarsino, S. and Magenes, G. Review of out-of-plane seismic assessment techniques applied to existing masonry 
buildings. Int. J. Archit. Herit. (2017) 11(1):2-21.

[6] Giaretton, M., Valluzzi, M.R., Mazzon, N. and Modena, C. Out-of-plane shake-table tests of strengthened multi-leaf stone masonry walls. Bull. Earthq. Eng. (2017) 15:4299-4317.

[7] De Santis, S., De Canio, G., de Felice, G., Meriggi, P. and Roselli I. Out-of-plane seismic retrofitting of masonry walls with Textile Reinforced Mortar composites. Bull. Earthq. Eng. (2019a) 17(11):6265-6300.

[8] Graziotti, F., Tomassetti, U., Penna, A. and Magenes, G. Out-of-plane shaking table tests on URM single leaf and cavity walls. Eng. Struct. (2016) 125:455-470.

[9] Costa, A.A., Arêde, A., Costa, A. and Oliveira C.S. Out-of-plane behaviour of existing stone masonry buildings: experimental evaluation. Bull. Earthq. Eng. (2012) 10(1):93-111.

[10] Derakhshan, H., Griffith, M.C. and Ingham, J.M. Airbag testing of multi-leaf unreinforced masonry walls subjected to one-way bending. Eng. Struct. (2013) 57:512-522.

[11] Roselli, G., Mirabile Gattia, D., AlShawa, O., Cinaglia, P., Di Girolami, G., Francola, C., Persia, F., Petrucci, E., Piloni, R., Scognamiglio, F., Sorrentino, L., Zamponi S. and Liberatore, D. Mortar analysis of historic buildings damaged by recent earthquakes in Italy Eur. Phys. J. Plus (2019) 134:540.

[12] De Canio, G., de Felice, G., De Santis, S., Giocoli, A., Mongelli, M., Paolacci, F. and Roselli, I. Passive 3D motion optical data in shaking table tests of a SRG-reinforced masonry wall. Earthq. Struct. (2016) 10(1):53-71

[13] Mongelli, M., Roselli, I., De Canio, G., and Ambrosino, F. Quasi real-time FEM calibration by 3D displacement measurements of large shaking table tests using HPC resources. $A d v$.

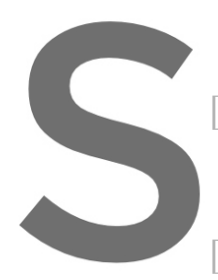
Eng. Softw. (2016)

[14] Papanicolaou, strengthening and (2011) 25(2):504-51

15] Babaeidarabad, S., De Caso, F. and Nanni

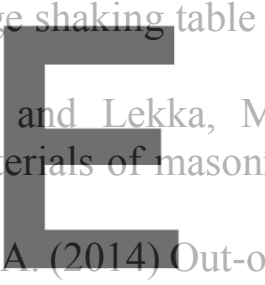
Strengthened with Fabric-Reinforced Cementitious Matrix Composite. J. Compos. Constr.

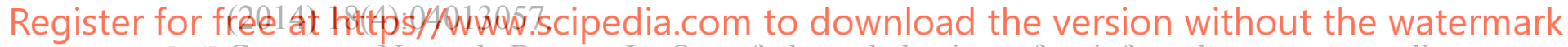

[16] Gattesco, N. and Boem, I. Out-of-plane behavior of reinforced masonry walls: Experimental and numerical study. (2017) Compos. Part B Eng. (2017) 128:39-52.

[17] De Santis, S., de Felice, G., Di Noia, G., Meriggi, P. and Volpe, M. Shake table tests on a masonry structure retrofitted with composite reinforced mortar. Key Eng. Mater. (2019b) 817:342-349.

[18] ACI 549R-97 State-of-the-art Report on Ferrocement. Farmington Hills, US (1997).

[19] Brameshuber, W. Textile reinforced concrete. State-of-the-art report of RILEM Technical Committee 201-TRC. Report 36, Bagneux, RILEM (2006).

[20] Corradi, M., Borri, A., Castori, G. and Sisti, R. The Reticulatus method for shear strengthening of fair-faced masonry Bull. Earthq. Eng. (2016) 14(12):3547-3571.

[21] ACI 549 0L - RILEM TC 250-CSM: Guide to Design and Construction of Externally Bonded Fabric-Reinforced Cementitious Matrix (FRCM) and Steel-Reinforced Grout (SRG) Systems for Repair and Strengthening Masonry Structures (2020).

[22] Meriggi, P., de Felice, G. and De Santis, S. Design of the out-of-plane strengthening of masonry walls with fabric reinforced cementitious matrix composites. Constr. Build. Mater. (2019) DOI: 10.1016/j.conbuildmat.2019.117946. 